\title{
Benefits of dietary sesame seed and flaxseed to strengthen immune system during COVID-19 pandemic and prevent associated comorbidities related health risks
}

\author{
S Rehan Ahmad* and Pritha Ghosh* \\ Department of Zoology, H M M College for Women, Kolkata-700035, West Bengal, India \\ *National Institute of Nutrition-ICMR, Tarnaka, Hydrabad-500007, Telangana State, India
}

\section{Article Info}

Article history

Received 28 October 2020

Revised 18 December 2020

Accepted 20 December 2020

Published online 30 December 2020

Keywords
Immune system
Sesame seed
Flaxseed
Antioxidant
Anti-inflammation
Comorbidities

\begin{abstract}
COVID-19 pandemic situation has created massive social and economic crisis globally and poses huge risks to survival of vulnerable, economically weaker groups, mainly in low-income and middle-income countries. Mortality appears to be high among persons with low immunity, poor nutritional status (malnourished) and associated comorbidities. Improve immune functions through nutrition is the most effective strategy to combat COVID-19 and other related viral infections. It is a long term process to improve immune power through a diverse and well balanced diet, but most significant during this unpredictable time when appropriate drug or vaccine is not available to prevent this viral infection. As strong immune system helps to recover any infectious disease conditions within a short period of time. This content is related to the link between nutrition, coronavirus disease 2019 (COVID-19), and the immune system. Main purpose of this content is to support the principle that diet rich in antioxidant and biologically active functional ingredients could be an effective nutritional intervention to restore the immune response, reduce inflammation and oxidative stress. Importance of flaxseed and sesame seed in the nutrition sector is because of their functional and highly active food ingredient. Those active food compounds have also health benefits against comorbidities in the COVID-19 patients including cardiovascular disease, hypertension, diabetes, cancer and various respiratory diseases. However, it is well established that due to influence of various nutritious components and bioactive molecules flaxseed and sesame seed playing critical roles in immune system. Daily dietary consumption of these foodstuffs helps to build up immunity against infectious disease and prevents COVID-19 related mild to chronic inflammations.
\end{abstract}

\section{Introduction}

COVID-19 is caused by severe acute respiratory syndrome coronavirus 2 (SARS-CoV-2), which is a positive-stranded RNA virus and transmitted through respiratory droplets. SARS-CoV-2 is easily attached to angiotensin-converting enzyme 2 (ACE2) receptors through spike glycoproteins, which is present on the envelope of the virus. ACE2 receptors are highly expressed by lung epithelial cells, cells of the heart, liver, bladder, gastrointestinal tract, kidney which makes them the main targets of the virus. One of the reasons for the higher infection rate among the adult population than children is the higher expression of the ACE2 receptors. Incubation period of this virus is around 3-7 days (ranging from 2-14 days). COVID-19 virus mainly affects respiratory system. Common clinical symptoms of this infection are fever, cough, breathing difficulties, and other nonspecific symptoms such as fatigue, headache, muscle

Corresponding author: Dr. S Rehan Ahmad

Assistant Professor, Department of Zoology, H M M College for Women, Kolkata-700035, West Bengal, India

E-mail: zoologist.rehan@gmail.com

Tel.: +91-9332094070

Copyright (c) 2020 Ukaaz Publications. All rights reserved.

Email: ukaaz@yahoo.com; Website: www.ukaazpublications.com pain, dyspnea, digestive symptoms, vomiting, and diarrhea. Severe conditions ultimately lead to pneumonia, acute respiratory distress syndrome (ARDS), multiorgan dysfunction (Li et al., 2020; Ouassou et al., 2020). Optimal nutritional balance is one of the effective ways to prevent any type of viral infection including COVID-19, maintain immunity at the individual level. Nutritional intervention can improve well-being and control harmful health consequences such as diabetes, hypertension, and excess body weight/obesity. Negative nutritional status can increase the infection rate, viral load, mortality rate and delayed recovery from infections (Naja et al., 2020). Nutritional modulation of the immune system is the most acceptable way to boost up immune system and suppress the infection progression rate during this pandemic situation (Derbyshire et al., 2020). Functional foods have many positive effects like mitigating various metabolic, non-communicable and infectious diseases along with basic nutritive values. Polyunsaturated fatty acids (PUFAs), phytosterols, antioxidants probiotics, prebiotics, symbiotics are commonly known as functional ingredients (Granato et al., 2020). According to the World Health Organization (WHO) and Centers for Disease Control and Prevention comorbidities such as cardiovascular diseases, diabetes, chronic respiratory disease, HIV, liver disease, renal disease, asthma, hypertension, obesity, 
cancer increases the COVID-19 (SARS-CoV-2) infection risk and shows poor clinical outcomes at the time of treatment. (Ejaz et al., 2020; Guan et al., 2020) (CDC, 2020) (WHO, 2020). Poor diet, unhealthy lifestyle, negative nutritional balance in the body are some common and major contributors to chronic metabolic, noncommunicable diseases such as cardiovascular disease, obesity, type 2 diabetes and many others. Therefore, the most effective approach to manage infection related risk factors is the optimization of nutrient intake through nutrient dense food stuff along with good hygiene practices during food handling.

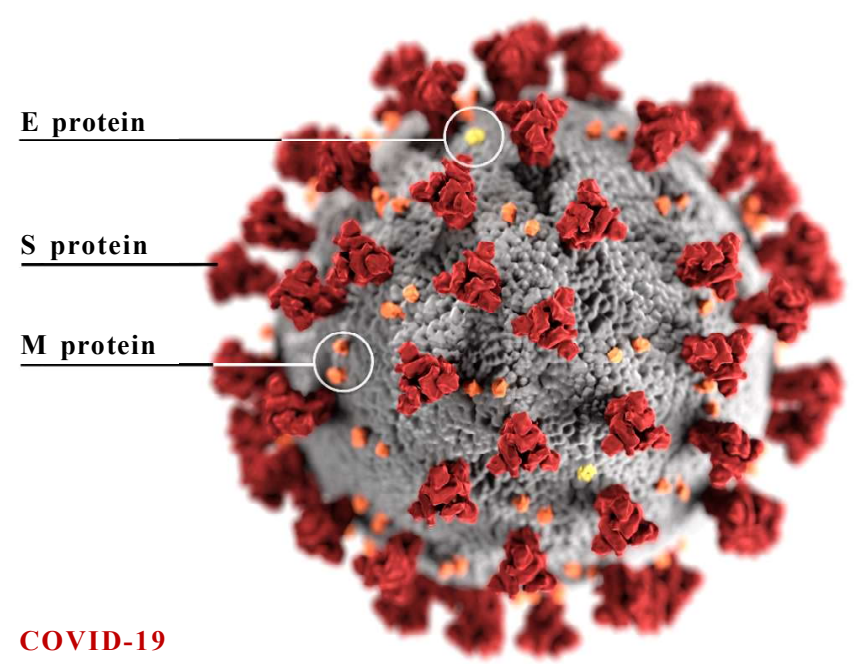

Corona virus - Photo credit: CDC/Alissa Eckert, MS; Dan Higgins, MAMS (Source: Khan et al., 2020: The COVID-19 pandemic: A scoping review.)

\section{Immune response in COVID-19}

Millions of people throughout the world affected by (SARS-CoV-2) during (COVID-19) pandemic. Low inflammation and oxidation stress are always associated with a healthy immune system. Imbalance among reactive oxygen, reactive nitrogen species (lipid peroxides, nitric oxide, singlet oxygen) endogenous and exogenous antioxidant activity resulting oxidative stress in the human body. Reactive oxidative species (ROS) can be produced and accumulated in the body due to endogenous antioxidant defense mechanisms which leads to oxidative stress. Immune cells like macrophages produce free radicals during infection and elevate oxidative stress consequently (Ntyonga-Pono $\mathrm{M}$ et al., 2020). Cytokines such as interleukin- $1 \beta$, tumor necrosis factor- $\alpha(\mathrm{TNF}-\alpha)$, interleukin- 6 are released due to onset of infection associated inflammatory stimulus, which ultimately mediate inflammation via activation of toll-like receptors (TLRs), TNF-receptor, IL-6 and IL-1 receptors (Iddir et al., 2020). In SARS-CoV-2 infection, S glycoprotein present on the envelope binds with ACE2, which stimulate toll-like receptor-7 (TLR-7) and further secretion of inflammatory cytokines (IL-1, IL-6, MIP-1A, TNF- $\alpha$, monocyte chemo attractant protein-1 (MCP1), interferon 1 (IFN1). During SARS-CoV-2 infection also inflammatory markers like IFN- $\gamma$, IL- $1 \beta$, IL-4, MCP-1, IP-10 and IL-10 level increases because of systemic inflammatory responses. In case of ICU patients elevated concentration of IL-7, IL-2, IL-10, IP-10, MCP-1, granulocyte-colony stimulating factor (GCSF), TNF- $\alpha$, macrophage inflammatory proteins (MIP-1A) are clearly noticeable in plasma (Fu et al., 2020). Cytokine storm is very common during COVID-19 infection because of host tissue damage by innate immunity of the body. Cytokine storm is a result of chronic T cells stimulation and exhaustion, which decreases body defense mechanisms and puts the patient into a more dangerous situation. Cytokine storm further leads to accumulation of fluid within lung tissue, alveolar damage, lung injury and respiratory failure (ARDS) that is the main reason for death after COVID-19 infection due to diminished acquired immune response (lower amount of lymphocytes, $\mathrm{CD}^{+}$and $\mathrm{CD} 4^{+}$) of the body. Decrease free radical oxidative stress (ROS) and inflammatory cytokines by supplying adequate antioxidant is one of the effective pathways to combat against COVID-19 infection related consequences (Calder et al., 2020; Horowitz et al., 2020).

\section{Bioactive components of sesame seed}

Sesame seed (Sesamum indicum L.) is known as the queen of oilseeds due to its unique property such as high oil content, flavor and aroma. Popularity of sesame seed is continuously increasing due to its various health benefits (Myint et al., 2020) (Parsaeian et al., 2020). Sesame (Sesamum indicum L.) is a member of Pedaliaceae family and Sesamum genus. Another name of sesame seed is Gingelly seed (Til) which is one of the widely popular edible oil in India. Composition of the sesame seed is dependent upon variety, various environmental factors, genetic variation, climate, harvesting time, cultivation and ripening stage. White, red or brown and black are most popular three varieties (Shamim et al., 2019). Sesame is a good source of oil (Soxhlet extraction process) and seed extracted oil has moderate to high concentration of phytochemicals, phytosterols (400 mg/100 g) (Sachin et al., 2018) (Pathak et al., 2017). The oil content of sesame seed is ranging from $39 \%$ to $49 \%$ and protein content around $20 \%$ (mainly glutamic, arginine aspartic acid, methionine and tryptophan) (Dar et al., 2019) (V. N. Gohil et al., 2018) (Khan et al., 2020). Sesame seed is a rich source of unsaturated fatty acids ( $83 \%-90 \%)$, mainly linoleic acid (37\%-47\%), followed by oleic acid (35\%-43\%), stearic acid (5\%$10 \%)$, palmitic acid $(9 \%-11 \%)$ and trace amount of linolenic acid also present in it (Pathak et al., 2017). Besides macronutrients, sesame has also considerable amount of lignans (sesamin, sesamolin), tocopherol, phenolics, flavonoids and minerals such as calcium, magnesium (182.47 mg/100 g of seed), phosphorous, iron (7.37 $\mathrm{mg} / 100 \mathrm{~g}$ of seed), copper, manganese, zinc $(4.47 \mathrm{mg} / 100 \mathrm{~g}$ of seed), magnesium and vitamin B1 (Pathak et al., 2017) (Dar et al., 2019) (Dravie et al., 2020). Quality of oil extracted from black sesame seed is best and used for various medicinal purposes (Shamim et al., 2019). Roasted sesame seeds used on the top of bread surface, desserts, salads cookies, breadsticks, ice creams, chocolates and mechanically hulled sesame seeds generally used in candies, sweet wholesome tahini, cakes, pastries, rolls, crackers in commercial bakeries. Refined sesame oil has high self shelf due to presence of antioxidants in it (Nagendra et al., 2012). Oil bearing seeds shows higher concentration of protein than other cereals seeds (Salama et al., 2015) 
3.1 Antioxidant and anti-inflammatory activities sesame seed

Antioxidant properties are expected to contribute a better immunesystem. Antioxidants have the ability to prevent free radical damage during increased oxidative stress, increase the number of $\mathrm{T}$ cell subsets, interleukin-2 production, natural killer cell activity (Uscogiuri et al., 220). Sesame seeds possess significant antioxidant activity due to presence of tocopherols, polyphenols and lignans. Antioxidant properties of sesame seed and extracted oil are important to slow down the oxidative deterioration process of lipids within it, which ensures prolong shelf-life of the oil and its nutritional quality (Wan et al., 2015) (Abirached et al., 2020). Sesame lignans showed immunomodulatory and hypocholesterolemic effects especially when consuming with tocopherol (Nagendra et al., 2012). The order of antioxidant activity of the three lignans is sesamol $>$ sesamin $>$ sesamolin. Antioxidant effect of sesamol shows scavenging effects against superoxide anion $\left(\mathrm{O}_{2}{ }^{--}\right)$, hydroxyl $\left(\mathrm{OH}^{\circ}\right)$, hydrogen peroxide $\left(\mathrm{H}_{2} \mathrm{O}_{2}\right)$, nitric oxide and related other oxidants due to the presence of hydroxyl group (Castro-González et al., 2020) (Mahendra et al., 2015). Sesamol is very effective antioxidant against lipid peroxidation, microsomal peroxidation and excess low density lipoprotein accumulation within circulatory system (Jayaraj et al., 2020). Chandrakala et al. (2015) confirmed the anti-inflammatory activity (down-regulated proinflammatory cytokines) of sesame oil and sesamin by using low-density lipoprotein receptor knockout $\left(\mathrm{LDLR}^{-/}\right)$female mice (Narasimhulu et al., 2015). Average tocopherol content of sesame seed is $292 \mu \mathrm{g} / \mathrm{g}$. Specifically, $S$. indicum species have highest amount of tocopherol content around $339.44 \mu \mathrm{g} / \mathrm{g}$. Gamma-tocopherol predominantly present within seed followed by alpha-tocopherol and deltatocopherol (Martinchik et al., 2011; Pathak et al., 2014) (Kim et al., 2020). Additionally, sesame seed and sesamin both are effective to increase hepatic gamma-tocopherol level (Hanzawa et al., 2013). In vivo experiments on rat model showed elevated amount of tocopherol concentration mainly gamma-tocopherol in plasma and increased its bioactivity after consumption of moderate amounts of sesame seeds (Cooney et al., 2001). Vitamin E (tocopherol) is potentially beneficial for its antioxidant, immunomodulatory effects which help to improve humoral and cellular immunity (T lymphocyte-mediated immune function), enhancing natural barriers against pathogen, phagocytosis, production of antibodies and lower respiratory tract infections in elderly. It also suppresses the production of inflammatory markers such as IL- 6 , and (TNF)- $\alpha$ after pathogenic invasion. For these beneficial roles it may be used against the COVID-19 virus and reduce the infection risk (Khorrami et al., 2018; Lewis et al., 2019; Jayawardena et al., 2020; Jovic et al., 2020; Akhtar et al., 2020; Fernández-Quintela et al., 2020).

\subsection{Potential role of sesame seed in COVID-19}

Addition of sesame seeds in our daily diet in various forms during this pandemic situation shows various health benefits (Kumar, 2020). Black sesame is also safe for dietary consumption during SARS-CoV-2 viral infection (Shirani et al., 2020). In silico analysis confirmed natural antioxidants like sesamin can effectively inhibit SARS-CoV-2 activity through attaching and interacting with active site residue Cys 145 of the SARS-CoV-2 virus, which leads to further control of viral replication process (Pandey et al., 2020). Numerous studies support the use of sesame oil to prevent viral infection rate due to its unique physical and chemical properties. These are low surface tension, high viscosity, antivirus activity, high-boiling point, and low hydrophobicity of mucosal surface. Nasal coating by Sesame oil gives large area of protective layer against viral attachment and due to its high boiling point (about $21^{\circ} \mathrm{C}$ ) protective layer stays longer. Sesame oil can easily entrap infectious during breathing and decrease direct viral contamination at the entry point (Fan et al., 2020). Nik et al., (2020) explained the mechanism through which unsaturated fatty acid incorporation into the lipid membrane of the viral envelope and destabilized viral membrane bilayer. By following this method sesame oil may inhibit infection rate of coronavirus. Yan et al., 2019 used human coronavirus 229E as a model coronavirus and stated that supplementation of linoleic acid (LA) and arachidonic acid (AA) significantly inhibited HCoV$229 \mathrm{E}$ virus replication. Apart from that Ayush guidelines for the COVID-19 also support the use of sesame oil for kavala or oil pulling and then warm water rinse to prevent infection risk (Ministry of Ayush, 2020).

\section{Bioactive components of flaxseed}

Flaxseed is a very popular and widely used plant based functional food. Flaxseed also known as linseed (Linum usitatissimum L.) and it belongs to the family Lineaceae. It is a rich source of lipids ( $\sim 41 \%$ ), protein $(\sim 22 \%)$, carbohydrates $(\sim 29 \%)$, and other essential micronutrients. It contains several essential minerals especially potassium $(5600-9200 \mathrm{mg} / \mathrm{kg})$, phosphorous $(650 \mathrm{mg} / 100 \mathrm{~g})$, magnesium $(350-431 \mathrm{mg} / 100 \mathrm{~g})$, calcium and sodium. Some minor components also present, those are cyanogenic glycosides, phenolics, trypsin inhibitor, phytic acid, linatine, phytoestrogens, vitamins, selenium, minerals, cadmium and cyclolinopeptides (CLs). Flaxseed oil is an excellent source of the omega-3 fatty acid ( $\sim 73 \%$ of total fatty acid) mostly $\alpha$-linolenic acid (ALA) with typical level of above $50 \%$. Bioavailability of $\alpha$-linolenic acid is more when flaxseed is consumed in oil form rather than in whole one (Rodriguez-Leyva et al., 2010). Polyunsaturated fatty acids, $v i z$, eicosapentaenoic acid and docosahexanoic acid are formed from ALA. Little amount of monounsaturated fatty acids ( 18\%) and saturated fatty acids $(\sim 9 \%)$ are also present (Punia et al., 2020). Flaxseed know as a 'superfood' due to its various health benefits including with tag of generally recognized as safe (GRAS), and significant percentages of $\omega-3$ polyunsaturated fatty acids make it one of the most popular functional food. Significant level of flaxseed lignans (75-800 times higher than any cereals, legumes, vegetables and fruits) and fibers (around 35-45\%) also shows lots of health benefits. Flaxseed is the richest source of plant lignans. Seed coat contains highest lignans, mainly secoisolariciresinol diglucoside (SDG). These plant lignans further converted into their active form in human body by metabolism of gut anaerobic bacteria. Out of total fiber content two-third is in insoluble form (cellulose, hemicellulose and lignin) and one third is in soluble form (mucilage) (Kajla et al., 2015; Dzuvor et al., 2018; Sanmartin et al., 2020). Generally people consume flaxseed as whole, milled, roasted and in oil form (Goyal et al., 2014). Nowadays, they are widely used in ready-to-eat breakfast cereals, multigrain bread, biscuits, salad 
dressings, crackers, and many other organic products. Excess consumption of saturated fatty acids leads to various metabolic disorders. In this situation flax-oil could be beneficial because substitution of saturated fatty acid with PUFAs ( $\omega-3$ and $\omega-6)$ protects against several metabolic disorders. Flaxseed improves immunity against viral infections along with manage cytokine storm and inflammatory mediators due to presence of $\omega-3$ PUFAs (Szabó et al., 2020; Thibault et al., 2020).

\subsection{Potential role of flaxseed in COVID-19}

Long chain polyunsaturated fatty acids play an important role in human health and disease through modulation of inflammatory mechanisms and innate immune response. $\omega$-3 PUFAs is an effective strategy to reduce the risk of viral infections if consumed in sufficient amount $(0.5 \%-2 \%$ of total calories). $\omega-3$ PUFAs also reduces excessive IL- 6 level and $\omega-3$ PUFAs derived protectins may suppress viral replication rate by blocking viral mRNA export (Messina et al., 2020) (Akrami et al., 2020). $\omega$-3 PUFAs improve phagocytosis activity of macrophages and macrophage related innate immunity (Hirayama et al., 2017) (Kumar, 2020) (Davanso et al., 2020). It is established that $\omega-3$ PUFAs suppress the nuclear p65 NF- $\kappa B$ translocation and reduces NF- $\kappa B$ activation. $\omega-3$ PUFAs also inhibit ERK1/2 MAPK activation and COX-2 production. Many hospitals prefer omega-3 fatty acids enriched enteral nutrition therapy for the patients of ARDS. Zhu et al. (2020) showed $\omega-3$ PUFAs in dietary flaxseed oil (FO) significantly reduce interleukin (IL)-1 $\beta$, (TNF)- $\alpha$, IL-6, IL-17A, fasting blood glucose (FBG), glycated hemoglobin, blood lipid, plasma lipopolysaccharide and inflammation in diabetic rat. Ren et al., proved by meta-analysis that flaxseeds and its derivatives can reduce C-reactive protein in obese populations. Zhang et al. stated that $\omega-3$ PUFAs including protectin D1, which is used to prepare antiviral drugs, is one of the effective interventions for this novel virus, COVID-19. They also said that ALA might be an optional therapy for this novel virus. $\omega-3$ PUFAs has immunomodulatory functions, which help to inhibit cytokines and (ROS) production. It can activate NK cells, T cells and enhance production of B cells, immunoglobulin (IgM) and ultimately strengthen the innate immunity (Chang et al., 2020).

\subsection{Effect of flaxseed to enhance gut immunity}

Healthy immune system is always essential for survival against any kind of infection related health risks. Gut microbiome associated immunity has a major role to prevent onset of infectious chronic diseases and related poor outcomes. Gut-associated lymphoid tissue (GALT) is the major site of immune cells within the human body. Gastrointestinal tract is the largest immune organ in mammals and it contains trillions of micro-organisms including bacteria, viruses, archae, and fungi. Maintaining healthy gut microbiota profile through nutrition can improve immunity among healthy population, geriatric population as well as immune compromised patients. Faulty dietary habits, antibiotic exposure can reduce the amount of good gut microbiota. Gut barrier provides protection against pathogenic infections through intercellular tight junctions, epithelial, mucus (physical gut barrier), maintaining acidity, bile salts, and proteolytic enzymes (trypsin). Dietary probiotic and prebiotic supplementation improves gut health and reduce gut inflammation. Plant based diet generally provides a nutrient diversity which is favorable for healthy gut microbiome. Probiotics are 'live micro-organisms, which, when consumed in adequate amounts, confer a health benefit of the host' and prebiotics are 'asubstrate that is selectively utilized by host micro-organisms conferring a health benefit' (Childs et al., 2019). 'Gut dysbiosis' leads to various chronic diseases like inflammatory bowel disease, type $2 \mathrm{DM}$, cardiovascular disease and many more. Even during old age gut microbiota diversity is reduced. Gut microbiota always support the functions and development of innate and adaptive immune system. Maintaining a healthy gut microbiome could be an effective way to reduce the chance as well as severity of the COVID-19 infection by maintaining the balance between anti-inflammatory (regulatory T cells) and pro inflammatory immune (Th17, IL-1, IL-6, TNF- $\alpha$ ) responses. Beneficial gut microbiota shows antiviral activity by direct interaction with pathogenic microorganisms, secretion of antiviral substances, and modulating immune system. Even gut dysbiosis may contribute the clinical manifestation in the COVID-19. Gut microbiota secreted small amount of short chain fatty acids (SCFA) such as acetate, butyrate, propionate which posses various immunomodulatory (Dhar et al., 2020) as well as anti-inflammatory properties (reduction of TNF- $\alpha$, IL-6, IL-1 $\beta$ ). SCFAs have ability to activate the functions of immune cells including $\mathrm{T}$ lymphocytes, neutrophils, macrophages and dendritic cells and stimulate anti-inflammatory cytokine IL-10 production. Prebiotics are able to increase immunity through up regulating anti-inflammatory cytokines expression and down regulating pro-inflammatory cytokines expressions. Prebiotics supports the production of butyrate in lower gastrointestinal tract which is well for its antiinflammatory functions during severe conditions in asthma and cystic fibrosis (Chaari et al., 2020). Healthy gut microbiome also helps to alter lung immunity and modulate pulmonary immune system during infection through gut-lung axis. Beneficial gut microbiota improves local immunity (via, gut wall integrity) as well as systemic immunity by improving specific and non-specific immunity. Probiotics are effective to enhance innate immune system through improving phagocytosis activity and microbicidal functions of leucocytes; natural killer (NK) cells (Sundararaman et al., 2020). Immunoglobulin A (IgA) secreted from subepithelial B-cells provides herd? immunity and protection against enteropathogens (Chassaing et al., 2014).

Flaxseeds are rich source of lignans mainly secoisolariciresinol diglucoside, which is 75-800 times more in these seeds than other fruits, vegetables, cereals grains, and legumes (Imran et al., 2015). Both soluble and insoluble fibers such as cellulose, hemicelluloses, mucilage gums, and lignin are present in flaxseed. Gut microbiota ferment those dietary fibers (gum, resistant starch, inulin, pectin) and produces various (SCFAs) like acetate, butyrate, and propionate. Due to production of SCFAs, flaxseed used as a prebiotic which promote gut health by modulating intestinal microbiota and gut microbial environment (Zarepoor et al., 2014). In vivo experiment in pig intestine showed flaxseed meal-containing diet (soluble fiber) enhanced microbial load (more than $2.2 \mathrm{log}$-folds) in the ileal digesta, mucosa and caecal mucosa of the pig models (Ndou et al., 2018). Mohamed et al., 2019 conducted an in vivo experiment 
to evaluate the effect of flaxseed oil on the gut microbiota. They selected male adult albino rats (Western) strain for their experiment and divided them into four groups. First group treated with saline (control), second group received flaxseed oil $(1 \mathrm{ml})$, third group treated with $1 \mathrm{ml}$ flaxseed oil nanoparticles and last group received $2 \mathrm{ml}$ flaxseed oil nanoparticles. They showed maximum bacterial count was with last group (received $2 \mathrm{ml}$ oil nanoemulsion) compared to other groups. Various in vivo experiments confirmed the positive effect of dietary fiber against viral infection. Gut microbiota ferments dietary fiber into short-chain fatty acids which shows some anti inflammatory functions. Dietary fermentable fiber supplementation and SCFAs production after fermentation promote both innate and adaptive immunity. Due to presence of high amount of both soluble and insoluble dietary fibers makes flaxseed are appropriate for gut health. Also soluble and insoluble fermentable fibers present in flaxseed helps to produce short chain fatty acids by gut microbiota and exhibit the growth and function of the healthy gut microbiota (Zhu et al., 2020).

\section{Effect of seed protein to prevent protein deficiency during infection}

The human body requires protein one of the essential macronutrients for proper functions of the body. Protein deficiency can be a major problem in economically weak countries due to low availability, unhealthy dietary pattern with low nutrients, consumption of highly processed food or junk food, and poor absorption rate. Protein deficiency leads to high risk of infection including decreased immunoglobulins and gut-associated lymphoid tissue (gut-mucosal defense system) activity. Dietary intake of sufficient amount of protein associated with anti inflammation. Protein rich foods with other essential macronutrients have potential to manage risk severity of viral infection. Protein requires for proper maintenance, nourishment and healing purposes of immune cells. In geriatric population protein supplement essential for maintenance of muscle mass, strength, and physical activity along with down regulate catabolic effects. Protein intake mainly from plant sources effectively reduces inflammation and oxidative stress and overall inflammatory burden (Hruby et al., 2019).

Protein content of faxseed varies from $10.5 \%$ to $31 \%$. Approximately, $73.4 \%$ of total protein is globulin fraction and remaining $26.6 \%$ is albumin (Ganorkar, 2013). Flaxseed proteins are comparatively high in arginine, aspartic acid, and glutamic acid than other amino acids. Analysis of different kind of cultivars confirmed the existence of six essential amino acids (21.06-50.65\% of total amino acids content) including methionine, threonine, valine, tryphtophan, phenylalanine, lysine and nine non-essential amino acids (49.35$78.94 \%$ of total amino acids content) including glutamic acid, glutamine, aspartic acid, asparagine, glycine, cystine, proline, alanine, serine. The essential amino acids concentration and composition of flaxseed are same as present in soybean (Shim et al., 2014; Kaur et al., 2017). Although, plant based protein is not consider as complete protein and don not have high biological value due to absence of one or more essential amino acids but flaxseed protein contributes some health benefits to protein deficient malnourished populations and those who are dependent on vegetable protein only (vegan or vegetarian population) and have milk protein intolerance and/or allergies. Gluten free flaxseed protein is safe for persons with gluten intolerance (Ganorkar, 2013). Flax protein isolates widely used as a nutritional supplementation to improve nutritional status and growth rate of infants with low birth weight due to presence of high amount of arginine and cysteine content. Analysis of amino acids profile of flax protein isolate showed lower ratio of lysine to arginine $(0.25)$ than whey protein isolate (WPI) (5.38), sodium caseinate (2.15) and soybean protein isolate (0.71). Low lysine to arginine ratio of flax protein isolate is beneficial for cardiac health because it has little effect on various cardiovascular risk factors and vascular reactivity (Vega-López et al., 2010; Kaushik et al., 2016). Apart from nutritional value flax protein isolate shows antioxidant property also mainly in acidic media (Mohamed et al., 2019). Bhathena et al., (2020) showed positive effect of dietary flaxseed protein on plasma lipid profile of rat models. Rats (F344) with normal lipid levels and obese rats (SHR/N-cp) with elevated cholesterol and triglyceride were used for this experiment. They proved dietary flaxseed protein suppressed plasma triglyceride, cholesterol level and fat deposition in livers of the both rat strains compared to soy protein (Bhathena et al., 2002).

Protein content in sesame seed varies between $18-25 \%$ (Oduma et al., 2020). Out of the storage protein content globulins present $67.3 \%$, followed by albumins $(8.6 \%)$, glutelins $(6.9 \%)$ and prolamines (1.4\%). Defatted sesame seed shows protein content upto $50 \%$. Sesame seed contains various amino acids such as arginine $(140 \mathrm{mg} / \mathrm{g}$ protein $)$, leucine $(75 \mathrm{mg} / \mathrm{g}$ protein $)$, methionine (36 mg/g protein), cystine $(25 \mathrm{mg} / \mathrm{g}$ protein) and moderate amount of lysine $(31 \mathrm{mg} / \mathrm{g}$ protein). Soybean protein is deficient in methionine $(16 \mathrm{mg} / \mathrm{g}$ protein) but high in lysine content $(68 \mathrm{mg} / \mathrm{g}$ protein), so that mixed diet with both soybean and sesame seed protein may be a good option to optimize nutritional value and protein quality (Namiki, 2007). After oil extraction procedure of sesame seed, remaining residue part (sesame seed meal) become an excellent source of protein (Baghban-Kanani et al., 2019). Sesame protein isolate can be used as a supplement to enrich amino acids content and improve nutritional compositions. Sesame protein isolate contains highest amount of glutamic acid among all the amino acids, followed by aspartic acid. Total amino acid content is $95.70 \mathrm{~g} /$ $100 \mathrm{~g}$ sesame protein isolate. Due to high protein digestibility and amino acids content sesame protein isolate supplementation could be a healthy way to reduce protein deficiency related health consequences especially in developing countries (Fasuan et al., 2018).

\section{Regulating COVID-19 associated comorbidities}

Individuals with non communicable diseases like diabetes, hypertension, cardiovascular diseases, chronic obstructive pulmonary disease (COPD), malignancies, HIV, and many others comorbidities are more prone to get COVID-19 infection compared to healthy individuals with healthy immune system. Comorbidities put anyone to a life-threatening situation during SARS-CoV-2 infection. SARS-CoV-2 virus attached with ACE-2 receptors for viral transmission. Some comorbid conditions strongly linked with ACE-2 receptor over expression. Comorbidity also stimulates the 
release of proprotein convertase which exhibit the viral transmission chance into the host cell. Moreover, comorbidities delay the outcome procedure and increase severity, mortality rate during COVID-19 infection [48]. One meta-analysis across mainland China showed $25.1 \%$ of the total positive patient (1590) had single comorbidity and $8.2 \%$ had more than one during admission. Commonly registered comorbidity was hypertension (16.9\%), followed by diabetes (8.2\%) [49]. One more meta-analysis (1576 COVID-19 infected patients) again confirmed that hypertension (21.1\%), diabetes (9.7\%) 95\% CI: 7.2-12.2\%), cardiovascular disease $(8.4 \%)$, and respiratory system disease $(1.5 \%)$ were the most prevalent comorbidities among hospitalized COVID-19 positive patients (Yang et al., 2020). 856 hospitalized COVID-19 positive cases investigated in China which showed hypertension (16.6\%) was the common comorbidity followed by diabetes $(7.5 \%)$ (Ye et al., 2020). Study conducted on patients with COVID-19 infection investigated that severe comorbid condition leads to poor recovery outcome and prolong hospital stays associated with ICU admission, mechanical intubation and death. Through managing these most prevalent comoridities we can reduce the severity of COVID-19 infection as well as control fatal events (Nandy et al., 2020).

Sesame seed extracted oil may control blood glucose level of persons with type 2 diabetes by activating hepatic antioxidant enzymes like superoxide dismutase, glutathione peroxidase and catalase. Sesame oil has positive on blood glucose level of type 2 diabetic individuals. Experiment was conducted on forty-six participants with type 2 diabetes. After 90 days of experiment, it was clear that sesame oil increased insulin level, hepatic antioxidant enzymes (catalase, superoxide dismutase, glutathione peroxidase) activities and lowered the $\mathrm{HbAlc}$ level, thiobarbituric acid reactive substances as well (Aslam et al., 2019). Study on 60 type 2 diabetes mellitus patients concluded that combination of sesame oil and glibenclamide had more significant anti hyperglycemic effect (36\% reduction of blood glucose level, and $43 \%$ reduction of $\mathrm{HbA}(1 \mathrm{c})$ compared to single therapy with only sesame oil. This combination therapy may be an effective and safe for further clinical practices in the field of hyperglycemia (Sankar et al., 2011). Ramesh et al. (2005) confirmed the positive effect of sesame oil on diabetic rats. They showed reduction of blood glucose along with reduced glycosylated hemoglobin level, and increased glucose-6phosphatase, fructose-1,6-bisphosphatase, hexokinase enzyme activation compared to control diabetic rats (Ramesh et al., 2005). Sesame seeds significantly reduce both systolic and diastolic blood pressure of hypertensive persons due to its antioxidant lignans (sesamin, episesamin, sesamol and sesamolin), fatty acids and vitamin E content (Cardoso et al., 2018). Use of sesame oil blend ( $20 \%$ unrefined lignans rich sesame oil with $80 \%$ refined $\gamma$-oryzanolrich rice bran oil) as a cooking oil for 60 days provided significant blood pressure (systolic, mean arterial, diastolic) reduction in mildto-moderate 400 hypertensive patients. Study group treated with both sesame oil blend and nifedipine showed maximum blood pressure reduction after experiment (Sankar et al., 2015). A metaanalysis with 843 participants provided evidenced that Sesame consumption directly associated with both systolic and diastolic blood pressure reduction (Khosravi-Boroujeni et al., 2017). Long term daily consumption of sesame oil increased endothelia functions of hypertensive men (Karatzi et al., 2013). Wichitsranoi et al. (2011) stated that black sesame meal decreased systolic BP, oxidative stress and improved vitamin E status. They selected 22 pre-hypertensive women and eight pre-hypertensive men for 4 weeks for their experiment (Wichitsranoi et al., 2011). Consumption of sesame oil significantly reduce body weight and body mass index also (Alipoor et al., 2012).

Flaxseed based products also effective to low both Systolic and diastolic blood pressure of hypertensive persons due to rich source of dietary $\alpha$-linolenic acid, lignans, and fiber. A meta-analysis with 1302 participants suggested that supplementation with flaxseed products inhibited both systolic and diastolic blood pressure among selected participants. Diastolic blood pressure reduction was visible after flaxseed powder and flax-oil supplementation but in case of flax-lignans effect was not visible (Ursoniu et al., 2016). In another meta-analysis (11 studies) also supported the fact that flaxseed supplementation reduced both systolic and diastolic blood pressure. Consumption of whole flaxseed for more than 12 weeks was more effective to maintain diastolic blood pressure (Khalesi et al., 2015). Flaxseed derived products like flax oil, flax lignan complex, secoisolariciresinol diglucoside, flaxseed protein hydrolysate also have direct effect on blood pressure reduction. Flaxseed, flax oil, and flax lignan can reduce blood pressure in hypertensive humans, and remaining secoisolariciresinol diglucoside, flaxseed protein hydrolysate shows positive effect on sprague dawley rats and spontaneously hypertensive rats (Prasad, 2019). Clinical trial on 80 hyperlipidemic and hypertensive patients showed flaxseed can reduce anthropometric measurements such as waist circumference, Waist to hip ratio and lipid profiles of individuals after daily consumption of $36 \mathrm{~g}$ of flaxseed for 8 weeks (Haghighatsiar et al., 2019). According to many human and animal studies flaxseed supplementation significantly decreases diabetes. One study investigated that flaxseed enriched yogurt (200 g yogurt with $30 \mathrm{~g}$ flaxseed) can control hyperglycemic condition (decreased hemoglobin A1c level), lipid profiles (reduced triglycerides and total cholesterol) and blood pressure (SBP and DBP) in type 2 diabetic individuals after 8 weeks of daily consumption (Hasaniani et al., 2019). (-3 fatty acids supplementation is essential during gestational diabetes mellitus because of its satisfactory positive effects on fasting plasma glucose, insulin resistance, insulin levels and insulin sensitivity (Jamilian et al., 2020). Flaxseed gums also very effective to maintain blood glucose and cholesterol level in the human body (Thakur et al., 2009).

Cardio protective effect of dietary antioxidants with flaxseed and $\alpha$-tocopherol were confirmed by using high fat fed diabetic golden Syrian hamsters (Haliga et al., 2015). Flaxseed based diet effective against obesity related risk factors also. Many clinical studies confirmed its effectiveness. 45 Randomized clinical trials suggested that flaxseed supplementation helps to reduce body weight, BMI and waist circumference. Subgroup analyses found a significant reduction in body composition after long term consumption of whole flaxseed body composition. So that whole flaxseed could be a good option for weight reduction diet (Mohammadi et al., 2017). 
Another randomized controlled trial performed on 68 patients with non alcoholic fatty liver disease for 12 weeks observed significant blood glucose and fat mass reduction after 12 weeks supplementation of flaxseed (Rezaei et al., 2020). One more clinical study found that sesame oil decreased systolic and diastolic blood pressure to normal level but again it increased when participants stopped sesame oil consumption. This study was conducted on 32 male and 18 female patients for 45 days and each participant used sesame oil as an edible oil throughout the study period. Reduction in body mass index, body weight, lipid peroxidation also noticed after the experiment (Sankar et al., 2006)

It is now well establish fact that COVID-19 infection is strongly associated with cardiovascular diseases. Preexisting cardiovascular disease may prolog hospital stays and poor outcomes. Further it leads to severe stage of COVID-19 infection and ultimate death. Even COVID-19 infection can cause various severe cardiac problems such as arrhythmia, myocardial injury, acute coronary syndrome and venous thromboembolism. Reduced physical activity during lockdown can be a risk factor for cardiovascular during this pandemic situation (Nishiga et al., 2020). 21 observational studies on 77317 hospitalized COVID-19 positive patients revealed that cardiovascular risk factors or comorbidities positive associated with high mortality rate among hospitalized patients. Out of the total hospitalized positive cases $12.86 \%$ had cardiovascular comorbidities and $14.09 \%$ showed cardiovascular complications during hospitalization period (Sabatino et al., 2020). Highly sensitive troponin level was observed $8-12 \%$ of all infected patients, which determined acute cardiac injury. Systemic inflammation and myocardial injury during COVID-19 infection were the major risk factors for cardiac disorder and associate health risks (Bansal, 2020).

Experiments on human and animal models stated that sesame seed and extracted oil both are very promising substances to control high cholesterol level, atherosclerosis, cardiovascular consequences and related inflammations due to presence of antioxidant and anti-inflammatory properties. It is very effective way to reduce low-density lipoprotein (LDL), triglycerides levels as well as maintain high-density lipoprotein (HDL) levels in human body. Lignans (sesamin and sesamol ) present in sesame seed have hypocholesterolemic and antioxidant effects (Hsu et al., 2017). Clinical randomized trial on 48 patients showed daily sesame oil (daily 4 table spoons) consumption for one month significantly reduced cholesterol, triglyceride, low density lipoprotein level, body Weight, waist measurement among participants. Sesame oil intake also elevated high density lipoprotein (HDL-C) level after the experiment (Namayandeh et al., 2013). One more experiment on high fat fed rabbit model clearly indicates that sesame oil supplementation can improve serum lipids profile (Asgary et al., 2013). Mainly in case of vitamin E, alpha-tocopherol and gammatocopherol are most significant in CVDs. Singh et al. (2007) conducted double blinded parallel study and showed gamma-T supplementation significantly reduce risk of thrombotic events and platelet activity by controlling lipid profile (Singh et al., 2007). Sesame derived sesamin can reduce the severity of endothelial dysfunction, atherosclerotic lesion, vascular inflammation and thrombosis by exhibiting NO bioactivity and decreasing the ROS production in blood vessels (Dalibalta et al., 2020). Food-based polyphenol is very active to control several cardiovascular diseases including oxidative stress related atherosclerosis, via stimulating Nrf-2 chemical signaling pathway and further reduction of foam cell formation on endothelial lining (Jayaraj et al., 2020). Daily administration of two different doses of sesame oil ( 5 and $10 \mathrm{ml} / \mathrm{kg}$ body weight) for one month provided significant protection against isoproterenol induced oxidative myocardial damage. Male Wistar albino rats were used for this experiment. Chronic sesame oil administration offered defense mechanism by suppressing thiobarbituric acid reactive substance, glutathione, catalase, superoxide dismutase and elevating endogenous antioxidant enzymes. Those mechanisms ultimately reduced oxidative myocardial injury and oxidative stress (Saleem et al., 2013). Experiment on Swiss albino mice model with hyperlipidemia showed that administration of 50 and $100 \mathrm{mg} / \mathrm{kg}$ body weight of sesamol not only significantly controlled cholesterol and triacylglycerol level of the mice model but also reduced the absorption rate of cholesterol as well (Kumar et al., 2013). To develop natural cardio protective drugs Sesame lignans could be a good option in future (Eweda et al., 2020).

Flaxseed is well known cardioprotective food due to its high amount of $\omega-3$ fatty acid (alpha linolenic acid), lignan and fiber. Bioactive compounds have anti-inflammatory, antioxidative properties (Rodriguez-Leyva et al., 2010; Parikh et al., 2019). In vivo experiment on novel rabbit model revealed that dietary flaxseed supplementation is very much effective against atherosclerotic plaque formation (approximately 40\% reduction). Along with this decrease in NF- $\kappa \mathrm{B}$ and proliferating cell nuclear antigen (PCNA) expression in vascular tissue also clearly visible after flaxseed supplementation. Alpha linolenic acid (ALA) helps to suppress atherosclerosis progression through inhibiting oxidation, inflammation and cell proliferation into vascular tissue (Francis et al., 2013). Another in vivo experiment by using LDLrKO mice model showed lower plasma cholesterol and saturated fatty acids level after supplementation of $10 \%(\mathrm{wt} / \mathrm{wt})$ ground flaxseed with cholesterol-enriched diet. Flaxseed supplementation with cholesterol exhibited plasma level of alpha linolenic acid and decreased plaque formation in the aorta and aortic sinus compared to only cholesterol fed mice. Dietary flaxseed supplementation reduced atherosclerosis risk in mice model due to anticholesteremic, antiproliferative and anti-inflammatory actions. Flaxseed based dietary supplement also stabilized various inflammatory markers like IL-6, mac-3, and VCAM-1 along with proliferating cell nuclear antigen (PCNA) expression (Dupasquier et al., 2007). Micro RNAs (miRs) including miR-1, miR-29b, miR-133a, miR-133b, miR-135a are associated with cardiac remodeling processes after myocardial infarction (MI). Flaxseed oil modulates miR-133a, miR135a, and miR-29b and shows cardioprotective effect in MI due to presence of high amount of alpha linolenic acid content (Parikh et al., 2020). Experiment on 40 male albino rats showed positive effect of flaxseed on acute myocardial ischemia after 6 weeks oral supplementation. Exercise training combined with flaxseed supplementation significantly elevated HDL level as well as antioxidant and anti-inflammatory paraoxonase 1. IL-1 $\beta$, Cardiac 
troponin, and TNF- $\alpha$ level decreased among flaxseed supplementation treated group compare to group with myocardial ischemia (Nounou et al., 2012). One randomized double-blind, placebo-controlled trial on 60 diabetic patients with coronary heart disease showed flaxseed oil supplementation for 12 weeks ( $1000 \mathrm{mg} \omega-3$ fatty acids from flaxseed oil) can modulate gene expression level of IL- 1 and TNF- $\alpha$, lipoprotein (a), and PPAR- $\gamma$ (Hashemzadeh et al., 2017). Flaxseed oil supplementation can reduce overactive endocannabinoid system associated coronary artery disease (Saleh-Ghadimi et al., 2020).

\section{Conclusion}

Now the COVID-19 pandemic is the most severe threats to health and the economy globally. As of now, there is no permanent and strong cure strategy to eliminate this novel infection, alternative methods need to be accepted to control the infection spreading. The inclusion of certain functional foods in our daily diet to maintain healthy immune system is not a final cure strategy for COVID-19 infection. Healthy lifestyle and eating patterns may optimize the immune system function and control the further progression of the infection into a severe state. Sesame seed and flaxseed consumption for a long time not only mitigate infection risk but also help to prevent malnutrition related health problem to some extent. Functional components of these oilseeds can control and inhibit co-morbidities related health risks. Moreover adequate dietary intake may be essential to protect against inflammatory response to SARS-CoV-2 infection, and preventing and improving its outcome.

\section{Acknowledgements}

I take pride in acknowledging the insightful guidance of Dr. Soma Ghosh, Principal, H M M College for Women, Kolkata, West Bengal, India, for sparing her valuable time whenever I approach her for help and support. I would also like to express my gratitude to my entire colleagues of H M M College for Women, Kolkata who have been so helpful and cooperative in giving their support at all times to help me to achieve my goal.

\section{Conflict of interest}

The authors declare that there are no conflicts of interest relevant to this article.

\section{References}

Abirached, C.; Bonifacino, C.; Dutto, E.; Velazco, L.; Jorge, F. and Vieitez, I. (2020). Study of sesame seeds antioxidant and emulsifying properties. The Journal of Supercritical Fluids, 166:104994. doi: https://doi.org/10.1016/j.supflu.2020.104994

Adnan A. Khan; Shiba, Khan; Unaiza, Khan and Kuntal, Das (2020). The COVID-19 pandemic: A scoping review. Ann. Phytomed., 9(1):18-26. http://dx.doi.org/10.21276/ap.2020.9.1.3

Ahmed, I.; AlJuhaimi, F.; Özcan, M. M.; Ghafoor, K.; Simsek, S.; Babiker, E. E.; Osman, M. A.; Gassem, M. A. and Salih, H. (2020). Evaluation of chemical properties, amino acid contents and fatty acid compositions of sesame seed provided from different locations. Journal of Oleo Science, 69(8):795-800. https://doi.org/10.5650/jos.ess20041

Akhtar, S.; Das, J. K.; Ismail, T.; Wahid, M.; Saeed, W. and Bhutta, Z. A. (2020). Nutritional perspectives for the prevention and mitigation of COVID-19. Nutrition Reviews, pp:nuaa063. https://doi.org/ $10.1093 /$ nutrit/nuaa063
Akrami, A.; Makiabadi, E.; Askarpour, M.; Zamani, K.; Hadi, A.; Mokari-Yamchi, A.; Babajafari, S.; Faghih, S. and Hojhabrimanesh, A. (2020). A comparative study of the effect of flaxseed oil and sunflower oil on the coagulation score, selected oxidative and inflammatory parameters in metabolic syndrome patients. Clinical Nutrition Research, 9(1):63-72. https://doi.org/10.7762/cnr.2020.9.1.63

Alipoor, B.; Haghighian, M. K.; Sadat, B. E. and Asghari, M. (2012). Effect of sesame seed on lipid profile and redox status in hyperlipidemic patients. International Journal of Food Sciences and Nutrition, 63(6):674-678. https://doi.org/10.3109/09637486.2011.652077

Asgary, S.; Rafieian-Kopaei, M.; Najafi, S.; Heidarian, E. and Sahebkar, A. (2013). Antihyperlipidemic effects of Sesamum indicum L. in rabbits fed a high-fat diet. The Scientific World Journal, pp:365892. https:// doi.org/10.1155/2013/365892

Aslam, F.; Iqbal, S.; Nasir, M. and Anjum, A. A. (2019). White sesame seed oil mitigates blood glucose level, reduces oxidative stress, and improves biomarkers of hepatic and renal function in participants with type 2 diabetes mellitus. Journal of the American College of Nutrition, 38(3):235-246. https://doi.org/10.1080/07315724.2018.1500183

Baghban-Kanani, P.; Hosseintabar-Ghasemabad, B.; Azimi-Youvalari, S.; Seidavi, A.; Laudadio, V.; Mazzei, D. and Tufarelli, V. (2019). Effect of dietary sesame (Sesame indicum L.) seed meal level supplemented with lysine and phytase on performance traits and antioxidant status of late-phase laying hens. Asian-Australasian Journal of Animal Sciences, 33(2):277-285. Advance online publication. https://doi.org/10.5713/ajas.19.0107

Bansal, M. (2020). Cardiovascular disease and COVID-19. Diabetes and Metabolic Syndrome, 14(3):247-250. https://doi.org/10.1016/ j.dsx.2020.03.013

Bhathena, S. J.; Ali, A. A.; Mohamed, A. I.; Hansen, C. T. and Velasquez, M. T. (2002). Differential effects of dietary flaxseed protein and soy protein on plasma triglyceride and uric acid levels in animal models. The Journal of Nutritional Biochemistry, 13(11):684-689. https:// doi.org/10.1016/s0955-2863(02)00227-9

Calder, P.C. (2020). Nutrition, immunity and COVID-19. BMJ Nutrition, Prevention and Health 2020. doi: 10.1136/bmjnph-2020-000085

Cardoso, C. A.; Oliveira, G.; Gouveia, L.; Moreira, A. and Rosa, G. (2018). The effect of dietary intake of sesame (Sesamum indicum L.) derivatives related to the lipid profile and blood pressure: A systematic review. Critical Reviews in Food Science and Nutrition, 58(1):116-125. https://doi.org/10.1080/10408398.2015.1137858

Castro-González, L. M.; Alvarez-Idaboy, J. R. and Galano, A. (2020). Computationally designed sesamol derivatives proposed as potent Antioxidants. ACS Omega, 5(16):9566-9575. https://doi.org/ 10.1021/acsomega.0c00898

Centers for disease control and prevention. Morbidity and mortality weekly report (MMWR): Preliminary estimates of the prevalence of selected underlying health conditions among patients with coronavirus disease 2019-February 12-March 28. 2020. https:// www.cdc.gov/mmwr/volumes/69/wr/mm6913e2.htm?s cid $=\mathrm{mm} 6913 \mathrm{e} 2 \mathrm{w}$

Chang, J. P.; Pariante, C. M. and Su, K. P. (2020). Omega-3 fatty acids in the psychological and physiological resilience against COVID-19. Prostaglandins, Leukotrienes, and Essential Fatty Acids, 161: 102177. https://doi.org/10.1016/j.plefa.2020.102177

Childs, C. E.; Calder, P. C. and Miles, E. A. (2019). Diet and immune function. Nutrients, 11(8):1933. https://doi.org/10.3390/nu11081933 
Cooney, R. V.; Custer, L. J.; Okinaka, L. and Franke, A. A. (2001). Effects of dietary sesame seeds on plasma tocopherol levels. Nutrition and Cancer, 39(1):66-71. https://doi.org/10.1207/S15327914nc391_9

Dalibalta, Sarah; Majdalawieh, Amin and Manjikian, Herak. (2020). Health benefits of sesamin on cardiovascular disease and its associated risk factors. Saudi Pharmaceutical Journal, 10.1016/j.jsps.2020.08.018.

Dar, A. A.; Kancharla, P. K.; Chandra, K.; Sodhi, Y. S. and Arumugam, N. (2019). Assessment of variability in lignan and fatty acid content in the germplasm of Sesamum indicum L. Journal of Food Science and Technology, 56(2):976-986. https://doi.org/10.1007/s13197018-03564-x

Davanso, M. R.; Crisma, A. R.; Murata, G.; Newsholme, P. and Curi, R. (2020). Impact of dietary fatty acids on macrophage lipid metabolism, signaling and function. Immunometabolism, 2(1):e200008. https:// doi.org/10.20900/immunometab20200008

Derbyshire, E. and Delange, J. (2020). COVID-19: Is there a role for immunonutrition, particularly in the over 65 s? BMJ Nutrition, Prevention and Health, bmjnph-2020-000071. https://doi.org/ 10.1136/bmjnph-2020-000071

Dravie, Emmanuel; Kortei, Nii; Essuman, Edward; Tettey, Clement; Boakye, Adjoa and Hunkpe, Gaston. (2020). Antioxidant, phytochemical and physicochemical properties of sesame seed (Sesamum indicum L). Scientific African, 8:e00349. 10.1016/j.sciaf.2020.e00349.

Dupasquier, C. M.; Dibrov, E.; Kneesh, A. L.; Cheung, P. K.; Lee, K. G.; Alexander, H. K.; Yeganeh, B. K.; Moghadasian, M. H. and Pierce, G. N. (2007). Dietary flaxseed inhibits atherosclerosis in the LDL receptor-deficient mouse in part through antiproliferative and anti-inflammatory actions. American Journal of Physiology. Heart and Circulatory Physiology, 293(4):H2394-H2402. https:// doi.org/10.1152/ajpheart.01104.2006

Dzuvor, C.; Taylor, J. T.; Acquah, C.; Pan, S. and Agyei, D. (2018). Bioprocessing of functional ingredients from flaxseed. Molecules (Basel, Switzerland), 23(10):2444. https://doi.org/10.3390/molecules23102444

Ejaz, H.; Alsrhani, A.; Zafar, A.; Javed, H.; Junaid, K.; Abdalla, A. E.; Abosalif, K.; Ahmed, Z. and Younas, S. (2020). COVID-19 and comorbidities: Deleterious impact on infected patients. Journal of Infection and Public Health, S1876-0341(20)30594-3. Advance online publication. https://doi.org/10.1016/j.jiph.2020.07.014

Eweda, S. M.; Newairy, A.; Abdou, H. M. and Gaber, A. S. (2020). Bisphenol Ainduced oxidative damage in the hepatic and cardiac tissues of rats: The modulatory role of sesame lignans. Experimental and Therapeutic Medicine, 19(1):33-44. https://doi.org/10.3892/etm.2019.8193

Fan, Wen; Zeng, Jing and Xu, Yunfeng. (2020). A theoretical discussion of the possibility and possible mechanisms of using sesame oil for prevention of 2019-nCoV (COVID-19 coronavirus) from the perspective of colloid and interface science. doi: 10.13140/RG.2.2.31786.98248

Fasuan, T. O.; Gbadamosi, S. O. and Omobuwajo, T. O. (2018). Characterization of protein isolate from Sesamum indicum seed: In vitro protein digestibility, amino acid profile, and some functional properties. Food Science and Nutrition, 6(6):1715-1723. https://doi.org/ $10.1002 /$ fsn 3.743

Fernández-Quintela, A.; Milton-Laskibar, I.; Trepiana, J.; Gómez-Zorita, S.; Kajarabille, N.; Léniz, A.; González, M. and Portillo, M. P. (2020). Key aspects in nutritional management of COVID-19 patients. Journal of Clinical Medicine, 9(8):2589. https://doi.org/10.3390/jcm9082589

Francis, A. A.; Deniset, J. F.; Austria, J. A.; LaValleé, R. K.; Maddaford, G. G.; Hedley, T. E.; Dibrov, E. and Pierce, G. N. (2013). Effects of dietary flaxseed on atherosclerotic plaque regression. American Journal of Physiology. Heart and Circulatory Physiology, 304(12):H1743H1751. https://doi.org/10.1152/ajpheart.00606.2012
Fu, Y.; Cheng, Y. and Wu, Y. (2020). Understanding SARS-CoV-2-Mediated inflammatory responses: From mechanisms to potential therapeutic tools. Virologica Sinica, 35(3):266-271. https://doi.org/10.1007/ s 12250-020-00207-4

Ganorkar, Pravin. (2013). Flaxseed: A nutritional punch. International Food Research Journal, 20(2):519.

Goyal, A.; Sharma, V.; Upadhyay, N.; Gill, S. and Sihag, M. (2014). Flax and flaxseed oil: An ancient medicine and modern functional food. Journal of Food Science and Technology, 51(9):1633-1653. https:/ /doi.org/10.1007/s13197-013-1247-9

Granato, D.; Barba, F. J.; Bursaæ Kovaèeviæ, D.; Lorenzo, J. M.; Cruz, A. G. and Putnik, P. (2020). Functional foods: Product development, technological trends, efficacy testing, and safety. Annual Review of Food Science and Technology, 11:93-118. https://doi.org/ 10.1146/annurev-food-032519-051708

Guan, W. J.; Liang, W. H.; Zhao, Y.; Liang, H. R.; Chen, Z. S.; Li, Y. M.; Liu, X. Q.; Chen, R. C.; Tang, C. L.; Wang, T.; Ou, C. Q.; Li, L.; Chen, P. Y.; Sang, L.; Wang, W.; Li, J. F.; Li, C. C.; Ou, L. M.; Cheng, B. and Xiong, S. (2020). China medical treatment expert group for COVID-19. Comorbidity and its impact on 1590 patients with COVID-19 in China: A nationwide analysis. The European Respiratory Journal, 55(5): 2000547. https://doi.org/10.1183/13993003.00547-2020

Guidelines for Ayurveda Practitioner for COVID-19, GOI, Ministry of Ayush. https://www.ayush.gov.in/docs/ayurved-guidlines.pdf

Haghighatsiar, N.; Askari, G.; Saraf-Bank, S.; Feizi, A. and Keshmiri, H. (2019). Effect of flaxseed powder on cardiovascular risk factor in dyslipidemic and hypertensive patients. International Journal of Preventive Medicine, 10:218. https://doi.org/10.4103/ijpvm.IJPVM 56317

Haliga, R. E.; Mocanu, V. and Badescu, M. (2015). Antioxidative and antiatherogenic effects of flaxseed, $\alpha$-tocopherol and their combination in diabetic hamsters fed with a high-fat diet. Experimental and Therapeutic Medicine, 9(2):533-538. https:// doi.org/10.3892/etm.2014.2102

Hanzawa, F.; Nomura, S.; Sakuma, E.; Uchida, T. and Ikeda, S. (2013). Dietary sesame seed and its lignan, sesamin, increase tocopherol and phylloquinone concentrations in male rats. The Journal of Nutrition, 143(7):1067-1073. https://doi.org/10.3945/jn.113.176636

Hasaniani, N.; Rahimlou, M.; Ramezani Ahmadi, A.; Mehdizadeh Khalifani, A. and Alizadeh, M. (2019). The effect of flaxseed enriched yogurt on the glycemic status and cardiovascular risk factors in patients with type 2 diabetes mellitus: randomized, open-labeled, controlled study. Clinical Nutrition Research, 8(4):284-295. https://doi.org/ 10.7762/cnr.2019.8.4.284

Hashemzadeh, A. A.; Nasoohi, N.; Raygan, F.; Aghadavod, E.; Akbari, E.; Taghizadeh, M.; Memarzadeh, M. R. and Asemi, Z. (2017). Flaxseed oil Supplementation improve gene expression levels of PPAR- $\gamma, \operatorname{LP}(\mathrm{a})$, IL-1 and TNF- $\alpha$ in type 2 diabetic patients with coronary heart disease. Lipids, 52(11):907-915. https://doi.org/10.1007/s11745017-4295-5

Hirayama, D.; Iida, T. and Nakase, H. (2017). The phagocytic function of macrophage-enforcing innate immunity and tissue homeostasis. International Journal of Molecular Sciences, 19(1):92. https:// doi.org/10.3390/ijms 19010092

Horowitz, R. I. and Freeman, P. R. (2020). Three novel prevention, diagnostic, and treatment options for COVID-19 urgently necessitating controlled randomized trials. Medical Hypotheses, 143:109851. https://doi.org/10.1016/j.mehy.2020.109851 
Hruby, A. and Jacques, P. F. (2019). Dietary protein and changes in biomarkers of inflammation and oxidative stress in the framingham heart study offspring cohort. Current developments in nutrition, 3(5):nzz019. https://doi.org/10.1093/cdn/nzz019

Hsu, E. and Parthasarathy, S. (2017). Anti-inflammatory and antioxidant effects of sesame oil on atherosclerosis: A descriptive literature review. Cureus, 9(7):e1438. doi: 10.7759/cureus.1438.

Iddir, M.; Brito, A.; Dingeo, G.; Fernandez Del Campo, S. S.; Samouda, H.; La Frano, M. R. and Bohn, T. (2020). Strengthening the immune system and reducing inflammation and oxidative stress through diet and nutrition: Considerations during the COVID-19 crisis. Nutrients, 12(6):1562. https://doi.org/10.3390/nu12061562

Jamilian, M.; Tabassi, Z.; Reiner, Ž.; Panahandeh, I.; Naderi, F.; Aghadavod, E.; Amirani, E.; Taghizadeh, M.; Shafabakhsh, R.; Satari, M.; Mansournia, M. A.; Memarzadeh, M. R. and Asemi, Z. (2020). The effects of n-3 fatty acids from flaxseed oil on genetic and metabolic profiles in patients with gestational diabetes mellitus: A randomised, double-blind, placebo-controlled trial. The British Journal of Nutrition, 123(7):792-799. https://doi.org/10.1017/S0007114519003416

Jayaraj, Premkumar; Aluganti, Chandrakala; Rajagopalan, Sanjay; Parthasarathy, Sampath and Desikan, Rajagopal. (2020). Sesamol: A powerful functional food ingredient from sesame oil for cardioprotection. Food and Function, 11:1198-1210. doi: 10.1039/C9FO01873E

Jayawardena, R.; Sooriyaarachchi, P.; Chourdakis, M.; Jeewandara, C. and Ranasinghe, P. (2020). Enhancing immunity in viral infections, with special emphasis on COVID-19: A review. Diabetes and Metabolic Syndrome, 14(4):367-382. https://doi.org/10.1016/j.dsx.2020.04.015

Jovic, T. H.; Ali, S. R.; Ibrahim, N.; Jessop, Z. M.; Tarassoli, S. P.; Dobbs, T. D. Holford, P.; Thornton, C. A. and Whitaker, I. S. (2020). Could vitamins help in the fight against COVID-19? Nutrients, 12(9):E2550. https:/ /doi.org/10.3390/nu 12092550

Kajla, P.; Sharma, A. and Sood, D. R. (2015). Flaxseed-a potential functional food source. Journal of Food Science and Technology, 52(4):18571871. https://doi.org/10.1007/s13197-014-1293-y

Karatzi, K.; Stamatelopoulos, K.; Lykka, M.; Mantzouratou, P.; Skalidi, S.; Zakopoulos, N.; Papamichael, C. and Sidossis, L. S. (2013). Sesame oil consumption exerts a beneficial effect on endothelial function in hypertensive men. European Journal of Preventive Cardiology, 20(2):202-208. https://doi.org/10.1177/2047487312437625

Kaur, M.; Kaur, R. and Gill, B.S. (2017). Mineral and amino acid contents of different flaxseed cultivars in relation to its selected functional properties. Food Measure, 11:500-511. https://doi.org/10.1007/ s 11694-016-9417-x

Kaushik, P.; Dowling, K.; McKnight, S.; Barrow, C. J.; Wang, B. and Adhikari, B. (2016). Preparation, characterization and functional properties of flaxseed protein isolate. Food Chemistry, 197(Pt A):212-220. https://doi.org/10.1016/j.foodchem.2015.09.106

Khalesi, S.; Irwin, C. and Schubert, M. (2015). Flaxseed consumption may reduce blood pressure: A systematic review and meta-analysis of controlled trials. The Journal of Nutrition, 145(4):758-765. https:/ /doi.org/10.3945/jn.114.205302

Khalil, M. I.; Salih, M. A. and Mustafa, A. A. (2020). Broad beans (Vicia faba) and the potential to protect from COVID-19 coronavirus infection. Sudanese Journal of Paediatrics, 20(1):10-12. https://doi.org/ 10.24911/SJP.106-1585398078

Khorrami, S.; Daneshmandi, S. and Mosayeb, G. (2018). Sesame seeds essential oil and Sesamol modulate the pro-inflammatory function of macrophages and dendritic cells and promote Th2 response. Medical Journal of the Islamic Republic of Iran, 32:98. https:// doi.org/10.14196/mjiri.32.98
Khosravi-Boroujeni, H.; Nikbakht, E.; Natanelov, E. and Khalesi, S. (2017). Can sesame consumption improve blood pressure? A systematic review and meta-analysis of controlled trials. Journal of the Science of Food and Agriculture, 97(10):3087-3094. https://doi.org/10.1002/jsfa.8361

Kim, T. J.; Park, J. G.; Kim, H. Y.; Ha, S. H.; Lee, B.; Park, S. U.; Seo, W. D. and Kim, J. K. (2020). Metabolite profiling and chemometric study for the discrimination analyses of geographic origin of perilla (Perilla frutescens) and sesame (Sesamum indicum) seeds. Foods (Basel, Switzerland), 9(8):989. https://doi.org/10.3390/foods9080989

Kumar, Jitendra. (April, 2020). 19 Traditions and practices to boost immunity against COVID-19. NITI Aayog, Government of India. https://niti.gov.in/19-traditions-and-practices-boost-immunityagainst-covid-19

Kumar, Nitesh; Mudgal, Jayesh; Parihar, Vipan; Nayak, Pawan; Nampurath, Gopalan Kutty and Rao, Chamallamudi (2013). Sesamol treatment reduces plasma cholesterol and triacylglycerol levels in mouse models of acute and chronic hyperlipidemia. Lipids, 48(6):633638. doi: 10.1007/s11745-013-3778-2

Kumar, V. (2020). Macrophages: The potent immunoregulatory innate immune cells. Intech Open. https://doi.org/10.5772/intechopen.88013

Lewis, E. D.; Meydani, S. N. and Wu, D. (2019). Regulatory role of vitamin E in the immune system and inflammation. IUBMB Life, 71(4):487-494. https://doi.org/10.1002/iub.1976

Li, H.; Liu, S. M.; Yu, X. H.; Tang, S. L. and Tang, C. K. (2020). Coronavirus disease 2019 (COVID-19): Current status and future perspectives. International Journal of Antimicrobial Agents, 55(5):105951. https://doi.org/10.1016/j.ijantimicag.2020.105951

Mahendra Kumar, C. and Singh, S. A. (2015). Bioactive lignans from sesame (Sesamum indicum L.): Evaluation of their antioxidant and antibacterial effects for food applications. Journal of Food Science and Technology, 52(5):2934-2941. https://doi.org/10.1007/ s13197-014-1334-6

Martinchik, A. N. (2011). Nutritional value of sesame seeds. Vopr Pitan, 80(3):41-43. Russian. PMID: 21842753.

Messina, G.; Polito, R.; Monda, V.; Cipolloni, L.; Di Nunno, N.; Di Mizio, G.; Murabito, P.; Carotenuto, M.; Messina, A.; Pisanelli, D.; Valenzano, A.; Cibelli, G.; Scarinci, A.; Monda, M. and Sessa, F. (2020). Functional role of dietary intervention to improve the outcome of COVID-19: A hypothesis of work. International Journal of Molecular Sciences, 21(9):3104. https://doi.org/10.3390/ijms21093104

Mohamed, R. S.; Fouda, K. and Akl, E. M. (2019). Hepatorenal protective effect of flaxseed protein isolate incorporated in lemon juice against lead toxicity in rats. Toxicology Reports, 7:30-35. https:/ /doi.org/10.1016/j.toxrep.2019.12.001

Mohammadi Sartang, Mohsen; Mazloom, Z; Raeisi-Dehkordi, Hamidreza; Barati Boldaji, Reza; Bellissimo, N and Totosy de Zepetnek, Julia. (2017). The effect of flaxseed supplementation on body weight and body composition: A systematic review and meta-analysis of 45 randomized placebo-controlled trials. Obesity Reviews: An Official Journal of the International Association for the Study of Obesity. 18(9). doi: $10.1111 /$ obr. 12550

Myint, D.; Gilani, S.A.; Kawase, M.; Watanabe, K.N. (2020). Sustainable sesame (Sesamum indicum L.) Production through improved technology: An overview of production, challenges, and opportunities in myanmar. Sustainability, 12(9):3515. https:// doi.org/10.3390/su12093515.

Nagendra Prasad, M.N.; Sanjay, K.R.; Prasad, D.S.; Vijay, N.; Kothari, R. and Nanjunda Swamy, S. (2012). A review on nutritional and nutraceutical properties of sesame. J. Nutr. Food Sci., 2:127. doi: 10.4172/ 2155-9600.100012 
Naja, F. and Hamadeh, R. (2020). Nutrition amid the COVID-19 pandemic: a multi-level framework for action. European Journal of Clinical Nutrition, 74(8):1117-1121. https://doi.org/10.1038/s41430-0200634-3

Namayandeh, S. M.; Kaseb, F. and Lesan, S. (2013). Olive and sesame oil effect on lipid profile in hypercholesterolemic patients, which better? International Journal of Preventive Medicine, 4(9):1059-1062.

Namiki, M. (2007). Nutraceutical functions of sesame: A review. Critical Reviews in Food Science and Nutrition, 47(7):651-673. https:// doi.org/10.1080/10408390600919114

Nandy, K.; Salunke, A.; Pathak, S. K.; Pandey, A.; Doctor, C.; Puj, K.; Sharma, M.; Jain, A. and Warikoo, V. (2020). Coronavirus disease (COVID-19): A systematic review and meta-analysis to evaluate the impact of various comorbidities on serious events. Diabetes and Metabolic Syndrome, 14(5):1017-1025. https://doi.org/10.1016/j.dsx.2020.06.064

Narasimhulu, C. A.; Selvarajan, K.; Litvinov, D. and Parthasarathy, S. (2015) Anti-atherosclerotic and anti-inflammatory actions of sesame oil. Journal of Medicinal Food, 18(1):11-20. https://doi.org/ $10.1089 / \mathrm{jmf} .2014 .0138$

Nishiga, M.; Wang, D.W. and Han, Y. (2020). COVID-19 and cardiovascular disease: From basic mechanisms to clinical perspectives. Nat. Rev. Cardiol., 17:543-558. https://doi.org/10.1038/s41569-020-0413-9

Nounou, H.A.; Deif, M.M. and Shalaby, M.A. (2012). Effect of flaxseed supplementation and exercise training on lipid profile, oxidative stress and inflammation in rats with myocardial ischemia. Lipids Health Dis., 11:129. https://doi.org/10.1186/1476-511X-11-129

Ntyonga-Pono, M. P. (2020). COVID-19 infection and oxidative stress: An under-explored approach for prevention and treatment? The Pan African Medical Journal, 35(2):12. https://doi.org/10.11604/ pamj.2020.35.2.22877

Oduma, Onyale; Inyang, Ufot and Okongoh, Okema. (2020). Impact of partial replacement of peanut paste with sesame seed paste on the nutritional and anti-nutritional components of butter made from the blends. European Journal of Nutrition and Food Safety, pp:5366. doi: $10.9734 /$ ejnfs/2020/v12i630238

Ouassou, H.; Kharchoufa, L.; Bouhrim, M.; Daoudi, N. E.; Imtara, H.; Bencheikh, N.; ELbouzidi, A. and Bnouham, M. (2020). The pathogenesis of coronavirus disease 2019 (COVID-19): Evaluation and prevention. Journal of Immunology Research, pp:1357983. https://doi.org/10.1155/2020/1357983

Pandey, A. K. and Verma, S. (2020). An in silico evaluation of dietary components for structural inhibition of SARS-CoV-2 main protease. Journal of Biomolecular Structure and Dynamics, pp:1-7. Advance online publication. https://doi.org/10.1080/07391102.2020.1809522

Parikh, M.; Kura, B.; O'Hara, K. A.; Dibrov, E.; Netticadan, T.; Slezak, J. and Pierce, G. N. (2020). Cardioprotective effects of dietary flaxseed post-infarction are associated with changes in microRNA expression. Biomolecules, 10(9):1297. https://doi.org/10.3390/ biom 10091297

Parikh, M.; Maddaford, T. G.; Austria, J. A.; Aliani, M.; Netticadan, T. and Pierce, G. N. (2019). Dietary flaxseed as a strategy for improving human health. Nutrients, 11(5):1171. https://doi.org/10.3390/ nu 11051171

Parsaeian, M.; Shahabi, M. and Hassanpour, H. (2020). Estimating oil and protein content of sesame seeds using image processing and artificial neural network. Journal of the American Oil Chemists Society, 97(7). doi: 10.1002/aocs.12356.
Pathak, Khanin; Rahman, Syed; Bhagawati, Sudhansu and Gogoi, Bhabesh. (2017). Sesame (Sesamum indicum L.), an underexploited oil seed crop: Current status, features and importance: A review. Agricultural Reviews, 38(3). doi: 10.18805/ag.v38i03.8982.

Pathak, N.; Rai, A.K. and Saha, S. (2014). Quantitative dissection of antioxidative bioactive components in cultivated and wild sesame germplasm reveals potentially exploitable wide genetic variability. J. Crop Sci. Biotechnol., 17:127-139. https://doi.org/10.1007/ s12892-013-0112-8

Prasad, K. (2019). Importance of flaxseed and its components in the management of hypertension. The International Journal of Angiology: Official Publication of the International College of Angiology, Inc., 28(3):153-160. https://doi.org/10.1055/s-00391678691

Punia, S.; Sandhu, K.S. and Dhull, S.B. (2020). Kinetic, rheological and thermal studies of flaxseed (Linum usitatissiumum L.) oil and its utilization. J. Food Sci. Technol., 57:4014-4021. https://doi.org/ 10.1007/s $13197-020-04434-1$

Ramesh, B.; Saravanan, R. and Pugalendi, K.V. (2005). Influence of sesame oil on blood glucose, lipid peroxidation, and antioxidant status in streptozotocin diabetic rats. J. Med. Food, 8(3):377-381. doi: 10.1089/jmf.2005.8.377. PMID: 16176150.

Ren, G. Y.; Chen, C. Y.; Chen, G. C.; Chen, W. G.; Pan, A.; Pan, C. W.; Zhang, Y. H.; Qin, L. Q. and Chen, L. H. (2016). Effect of flaxseed intervention on inflammatory marker C-Reactive protein: A systematic review and meta-analysis of randomized controlled trials. Nutrients, 8(3): 136. https://doi.org/10.3390/nu8030136

Rezaei, S.; Sasani, M. R.; Akhlaghi, M. and Kohanmoo, A. (2020). Flaxseed oil in the context of a weight loss programme ameliorates fatty liver grade in patients with non-alcoholic fatty liver disease: A randomised double-blind controlled trial. The British Journal of Nutrition, 123(9):994-1002. https://doi.org/10.1017/S0007114520000318

Rodriguez-Leyva, D.; Dupasquier, C. M.; McCullough, R. and Pierce, G. N. (2010). The cardiovascular effects of flaxseed and its omega-3 fatty acid, alpha-linolenic acid. The Canadian Journal of Cardiology, 26(9):489-496. https://doi.org/10.1016/s0828$282 \times(10) 70455-4$

Sabatino, J.; De Rosa, S.; Di Salvo, G. and Indolfi, C. (2020). Impact of cardiovascular risk profile on COVID-19 outcome. A meta-analysis. PloS One, 15(8):e0237131. https://doi.org/10.1371/journal.pone.0237131

Sachin, B. Somwanshi; Shivanand, N. Hiremath and Rakesh, K. Jat. (2018). Standardization and phytochemical investigation of Sesamum indicum L. seed extract. J. Pharmacogn. Phytochem., 7(4):1293-1296.

Salama, Dr. Zeinab; Youssef, M.A.; Taie, Hanan and El-Baz, Farouk. (2015). Increasing omega 6, omega 9 fatty acids and oil contents in black sesame seed by biofertilizer and micronutrients application. International Journal of Pharmaceutical Sciences Review and Research, 31(1):256-261.

Saleem, M. T.; Chetty, M. C. and Kavimani, S. (2013). Putative antioxidant property of sesame oil in an oxidative stress model of myocardial injury. Journal of Cardiovascular Disease Research, 4(3):177-181. https://doi.org/10.1016/j.jcdr.2013.07.001

Saleh-Ghadimi, S.; Alizadeh, M. and Jafari-Vayghan, H. (2020). Effect of flaxseed oil supplementation on the erythrocyte membrane fatty acid composition and endocannabinoid system modulation in patients with coronary artery disease: A double-blind randomized controlled trial. Genes Nutr., 15:9. https://doi.org/10.1186/s12263020-00665-1 
Sankar, D.; Singh, Ravinder; Chatterjee, Biprabuddha; Zhang, Bo. and Ali, Amanat. (2015). A blend of sesame oil and rice bran oil lowers blood pressure and improves the lipid profile in mild-to-moderate hypertensive patients. Journal of Clinical Lipidology, pp:10. 10.1016/j.jacl.2015.12.011.

Sankar, D.; Ali, A.; Sambandam, G. and Rao, R. (2011). Sesame oil exhibits synergistic effect with anti-diabetic medication in patients with type 2 diabetes mellitus. Clinical Nutrition (Edinburgh, Scotland), 30(3):351-358. https://doi.org/10.1016/j.clnu.2010.11.005

Sankar, D.; Rao, M. R.; Sambandam, G. and Pugalendi, K. V. (2006). Effect of sesame oil on diuretics or Beta-blockers in the modulation of blood pressure, anthropometry, lipid profile, and redox status. The Yale Journal of Biology and Medicine, 79(1):19-26.

Sanmartin, C.; Taglieri, I.; Venturi, F.; Macaluso, M.; Zinnai, A.; Tavarini, S.; Botto, A.; Serra, A.; Conte, G.; Flamini, G. and Angelini, L. G. (2020) Flaxseed cake as a tool for the improvement of nutraceutical and sensorial features of sourdough bread. Foods (Basel, Switzerland), 9(2):204. https://doi.org/10.3390/foods 9020204

Shamim, Saad Ahmed. (2019). Medicinal properties of kunjad (Sesamum indicum L.): A review. Pharma Innovation, 8(6):926-931.

Shim, Youn; Gui, Bo; Arnison, Paul; Wang, Yong and Reaney, Martin. (2014). Flaxseed (Linum usitatissimum L.) bioactive compounds and peptide nomenclature: A review. Trends in Food Science and Technology, 3838(1). doi: 10.1016/j.tifs.2014.03.011

Shirani, K.; Sheikhbahaei, E.; Torkpour, Z.; Ghadiri Nejad, M.; Kamyab Moghadas, B.; Ghasemi, M.; Akbari Aghdam, H.; Ehsani, A.; SaberSamandari, S. and Khandan, A. (2020). A narrative review of COVID19: The new pandemic disease. Iranian Journal of Medical Sciences, 45(4):233-249. https://doi.org/10.30476/ijms.2020.85869.1549

Singh, I.; Turner, A. H.; Sinclair, A. J.; Li, D. and Hawley, J. A. (2007). Effects of gamma-tocopherol supplementation on thrombotic risk factors. Asia Pacific Journal of Clinical Nutrition, 16(3):422-428.

Szabó, Z.; Marosvölgyi, T.; Szabó, É.; Bai, P.; Figler, M. and Verzár, Z. (2020). The potential beneficial effect of EPA and DHA supplementation managing cytokine storm in coronavirus disease. Frontiers in Physiology, 11:752. https://doi.org/10.3389/fphys.2020.00752

Thakur, Goutam; Mitra, Analava; Pal, Kunal and Rousseau, Derick. (2009) Effect of flaxseed gum on reduction of blood glucose and cholesterol in type 2 diabetic patients. International Journal of Food Sciences and Nutrition. 60:1-11. doi: 10.1080/ 09637480903022735

Thibault, R.; Seguin, P. and Tamion, F. (2020). Nutrition of the COVID-19 patient in the intensive care unit (ICU): A practical guidance. Crit. Care, 24:447. https://doi.org/10.1186/s13054-020-03159-z

Ursoniu, S.; Sahebkar, A. andrica, F.; Serban, C. and Banach, M. (2016). Lipid and blood pressure meta-analysis collaboration (LBPMC) Group. effects of flaxseed supplements on blood pressure: A systematic review and meta-analysis of controlled clinical trial. Clinical Nutrition (Edinburgh, Scotland), 35(3):615-625. https://doi.org/ 10.1016/j.clnu.2015.05.012
Uscogiuri, G.; Barrea, L.; Savastano, S. and Colao, A. (2020). Nutritional recommendations for CoVID-19 quarantine. European Journal of Clinical Nutrition, 74(6):850-851. https://doi.org/10.1038/ s41430-020-0635-2

V. N. Gohil, B. A. M. (2018). GJT 5: Region specific high yielding sesame variety suitable for summer irrigated ecosystem. Electronic Journal of Plant Breeding, 9(1):154-159. Retrieved from http:// www.ejplantbreeding.org/index.php/EJPB/article/view/2295

Vega-López, S.; Matthan, N. R.; Ausman, L. M.; Harding, S. V.; Rideout, T. C.; Ai, M.; Otokozawa, S.; Freed, A.; Kuvin, J. T.; Jones, P. J.; Schaefer, E. J. and Lichtenstein, A. H. (2010). Altering dietary lysine:arginine ratio has little effect on cardiovascular risk factors and vascular reactivity in moderately hypercholesterolemic adults. Atherosclerosis, 210(2):555-562. https://doi.org/10.1016/j.atherosclerosis.2009.12.002

Wan, Y.; Li, H.; Fu, G.; Chen, X.; Chen, F. and Xie, M. (2015). The relationship of antioxidant components and antioxidant activity of sesame seed oil. Journal of the Science of Food and Agriculture, 95(13): 2571-2578. https://doi.org/10.1002/jsfa.7035

Wichitsranoi, J.; Weerapreeyakul, N.; Boonsiri, P.; Settasatian, C.; Settasatian, N.; Komanasin, N.; Sirijaichingkul, S.; Teerajetgul, Y.; Rangkadilok, N. and Leelayuwat, N. (2011). Antihypertensive and antioxidant effects of dietary black sesame meal in pre-hypertensive humans. Nutrition Journal, 10:82. https://doi.org/10.1186/1475-2891-10-82

World Health Organization. COVID-19 significantly impacts health services for noncommunicable diseases. (accessed on 1st June, 2020), https:// www.who.int/news-room/detail/01-06-2020-covid-19-significantlyimpacts-health-services-for-noncommunicable-diseases.

Yan, B.; Chu, H.; Yang, D.; Sze, K. H.; Lai, P. M.; Yuan, S.; Shuai, H.; Wang, Y.; Kao, R. Y.; Chan, J. F. and Yuen, K. Y. (2019). Characterization of the lipidomic profile of human coronavirus-infected cells: Implications for lipid metabolism remodeling upon coronavirus replication. Viruses, 11(1):73. https://doi.org/10.3390/v11010073

Yang, J.; Zheng, Y.; Gou, X.; Pu, K.; Chen, Z.; Guo, Q.; Ji, R.; Wang, H.; Wang, Y. and Zhou, Y. (2020). Prevalence of comorbidities and its effects in patients infected with SARS-CoV-2: A systematic review and metaanalysis. International Journal of Infectious Diseases: IJID: Official Publication of the International Society for Infectious Diseases, 94:91-95. https://doi.org/10.1016/j.ijid.2020.03.017

Ye, C.; Zhang, S.; Zhang, X.; Cai, H.; Gu, J.; Lian, J.; Lu, Y.; Jia, H.; Hu, J.; Jin, C.; Yu, G.; Zhang, Y.; Sheng, J. and Yang, Y. (2020). Impact of comorbidities on patients with COVID-19: A large retrospective study in Zhejiang, China. Journal of Medical Virology, 10.1002/jmv.26183. Advance online publication. https://doi.org/10.1002/jmv.26183

Zhang, L. and Liu, Y. (2020). Potential interventions for novel coronavirus in China: A systematic review. Journal of Medical Virology, 92(5):479-490. https://doi.org/10.1002/jmv.25707

Zhu, L.; Sha, L.; Li, K.; Wang, Z.; Wang, T.; Li, Y.; Liu, P.; Dong, X.; Dong, Y.; Zhang, X. and Wang, H. (2020). Dietary flaxseed oil rich in omega-3 suppresses severity of type 2 diabetes mellitus, via, anti-inflammation and modulating gut microbiota in rats. Lipids in Health and Disease, 19(1):20. https://doi.org/10.1186/s12944-019-1167-4

Citation Ahmad, S. R. and Ghosh Pritha (2020). Benefits of dietary sesame seed and flaxseed to strengthen immune system during COVID-19 pandemic and prevent associated comorbidities related health risks. Ann. Phytomed., 9(2):50-61. http://dx.doi.org/10.21276/ap.2020.9.2.5 